\title{
ESTUDO SISTEMÁTICO SOBRE O PROJETO AMA, COMUNIDADE AJÓ, MUNICÍPIO DE CAMETA-PA
}

\author{
Carla Braga Pereira ${ }^{(a)}$, Layse Gomes Furtado ${ }^{(b)}$ \\ (a) Faculdade de Geoprocessamento, Universidade Federal do Pará,Campus Ananindeuacarlabpereira10@ gmail.com \\ ${ }^{(b)}$ Faculdade de Geoprocessamento, Universidade Federal do Pará,Campus Ananindeua \\ layse.furtadog@gmail.com
}

\section{EIXO: BIOGEOGRAFIA, MANEJO DE ÁREAS NATURAIS E PROTEGIDAS: CONSERVAÇÃO DA BIODIVERSIDADE}

\begin{abstract}
Resumo:
O uso do espaço geográfico para manejo dos recursos naturais em detrimento do consumo próprio e o modo de produção para o meio externo, são algumas formas de subsistências das comunidades tradicionais que habitam a região Amazônica. E dentre tantos trabalhos comunitários a AMAAssociação das Mulheres Agroextrativistas da Comunidade de Ajó, Cametá-PA, desenvolve um trabalho conjunto que consiste na produção de polpas de frutas como manga, tapereba e cupuaçu, além da confecção de bombons de chocolate com recheios e doces dessas frutas e plantações de hortaliças para o consumidor final. Diante das dificuldades dessa associação por ausência dos órgãos responsáveis, como falta de incentivo, estrutura e financiamento de créditos fiscais, a mesma próspera pelos seus méritos e até alcançou prêmios nacionais como resultados de seu esforço e reconhecimento. Por fim almeja-se conhecer mais sobre o modo de produção, comercialização e a interação destes trabalhadores rurais com o meio natural.
\end{abstract}

Palavras chave:Agroextrativismo; subsistência; Comunidade de Ajó; Cameta- PA.

\section{Introdução}

O município de Cametá localiza-se na microrregião do Baixo Tocantins-PA, é caracterizado pela colonizaçãoeuropeia, marcada por grandiosos projetos, como a construção da barragem de Tucuruí que afetou substancialmente a população da região. Sua economia é marcada pelo pescado e produção agrícola. O município apresenta áreas de terra firme, várzea e campos naturais, além de possuirmais de cemilhas. A área que cobre a comunidade do Ajóoriginou-se a partir de duas outras propriedades, na primeira parte residiaum padre integrante da IgrejaCatólica e na segunda uma família antiga da região, algumas famílias vieram morar naquela localidade e prestar serviço ao padree por alguns anos receberam pequenas parcelas de terra como doação, após a morte do padre as terras foram destinadas a igreja que a dividiu em pequenos lotes e doou a maioria para as familias que migraram e para os membros das famílias mais antigas da região, e a outra parte dividiram novamente para descendentes das famílias antigas, assim originando o local onde a Associação dos Moradores do Ajó encontra-se. 
XVII Simpósio Brasileiro

de Geografia Fisica Aplicada

I Congresso Nacional

de Geografia Física
OS DESAFIOS DA GEOGRAFIA FÍSICA NA FRONTEIRA DO CONHECIMENTO

Instituto de Geociências - Unicamp

Campinas - SP

28 de Junho à 02 de Julho de 2017

O projeto começou em 2007 por um pequeno grupo e ao observarem que várias frutas não eraaproveitável resolveram utiliza-los para confeccionar doces de cupuaçu, manga, coco e bombons de chocolate com recheio das mesmas frutas mencionadas anteriormente. Em parceria com entidade de assessoria do município de Cametá - APAC (Associação Paraense que Apoia as Comunidades Carentes) criou-se o projeto PAA (Programa de Aquisição de Alimentos) via CONAB.

\section{Metodologia}

Para a confecção do presente resumo foi imprescindível anotar os relatos de agricultoras e da líder da Associação para entender os aspectos sociais, econômicos e espaciais da comunidade em questão, além da prática de campo fundadas em reconhecimento visual e prático da realidade das agriculturasfavoreceu uma dinamização maior do contexto em estudo.

\section{Objetivo}

O objetivo central do resumo é conhecer o projeto AMA atravésdo modo de produção, comercialização e a interação destes trabalhadores ruraiscom o meio natural, resultado de uma alternativa econômica para a subsistência das famílias integrantes desse projeto.

\section{Resultados e Discussão}

A sustentabilidade através do incentivo à diversificação das atividades produtivas e práticas alternativas de manejo e exploração do meio natural é hoje, aliás, um dos principais temas na agenda local de discussão sobre o desenvolvimento rural (Cardoso \& Tavares, 2016). A produção familiar extrativista no Baixo Tocantins-PA, foi ajustando-se com as transformações ocasionadas com a inserção dos grandes projetos; o comércio e as linhas de financiamentos de crédito, relacionada com a produção agroextrativista do local. Com a diversificação de culturas na região os camponeses tem-se permitido incorporar atividades como a criação de peixes e principalmente as diversas utilizações das espécies frutíferas e de reflorestamento.

Buscando uma forma de subsistência familiar aAssociação das Mulheres Agroextrativistas da Comunidade de Ajó - AMA encontrou em seu próprio meio natural a busca de uma renda complementar, por meio da produção de polpas de frutas como manga, tapereba, cupuaçu e acerola, além da confecção de bombons de chocolate com recheios e doces dessas frutas e plantações de hortaliças para o consumidor final.Na entre safra fazem pães caseiros, chocolates e bombos de cacau, hortaliças e também artesanatos. 
XVII Simpósio Brasileiro

de Geografia Fisica Aplicada

I Congresso Nacional de Geografia Física
OS DESAFIOS DA GEOGRAFIA FÍSICA NA FRONTEIRA DO CONHECIMENTO

Instituto de Geociências - Unicamp

Campinas - SP

28 de Junho à 02 de Julho de 2017

Vendem mingaus, bolos e sucos. O espaço de produção foi construído com a venda de produtos em mutirão (Consulado da Mulher, 2015).

Entretanto a necessidade de ter profissionais de Educação no Campo seria essencial para o reconhecimento de agricultores que fazem os plantios diferenciados e de maneira correta.

No inicio a iniciação do projeto foi bastante precária, onde as mulheres da associação empurravam as bicicletas para levar as polpas das frutas em uma estrada de piçarra sem condições de tráfego, sem energia elétrica, mostrando o sacrifício para atingir o seu objetivo, sinalizando a sua força, vontade e perseverança.

Em parceria com entidade de assessoria do município de Cametá - APAC (Associação Paraense que Apoia as Comunidades Carentes) criou-se o projeto PAA (Programa de Aquisição de Alimentos) via $\mathrm{CONAB}$, entretanto a infraestrutura no inicio das atividades era precária, portanto, aos poucos adquiriram o freezer, local de armazenamento e conservação das polpas de frutas, a máquina de açaí temporariamente serviu para despolpar frutas como manga, tapereba, caju e acerola.

Por meio de esforços o projeto foi ascendendo, onde no inicio o grupo era formado por 6 pessoas, atualmente é composto por 13 membros.

As etapas das atividades até ao produto final consistem no colhimento das frutas - lavagemarmazenamento em freezer- Despolpadora - Dosador - Seladora (Figura 1A, 1B, 1C e 1D).

Para a divulgação dos produtos a associação participa de feiras e eventos na cidade, entretanto ainda precisa do apoio da prefeitura, para questão de incentivo e infraestrutura.

Atualmente o projeto conta com uma sala equipada com os equipamentos necessários para a realização das atividades e outro espaço ainda em construção.

Em 2015, por meio de um novo projeto via Sindicatos dos Trabalhadores Rurais de Cametá, foram premiadas pela empresa Consulado Mulher, localizada em São Paulo, esse premio foi bastante apreciado, pois foi resultado de várias dificuldades que o grupo passou. O dinheiro do prêmio foi investido na construção de um espaço mais amplo para a realização das atividades, além da premiação de novos maquinários (3 freezers, 1 geladeira, 1 ar condicionado, 2 fogões, 1 purificador de água) e auxílio de nova assessoria. 


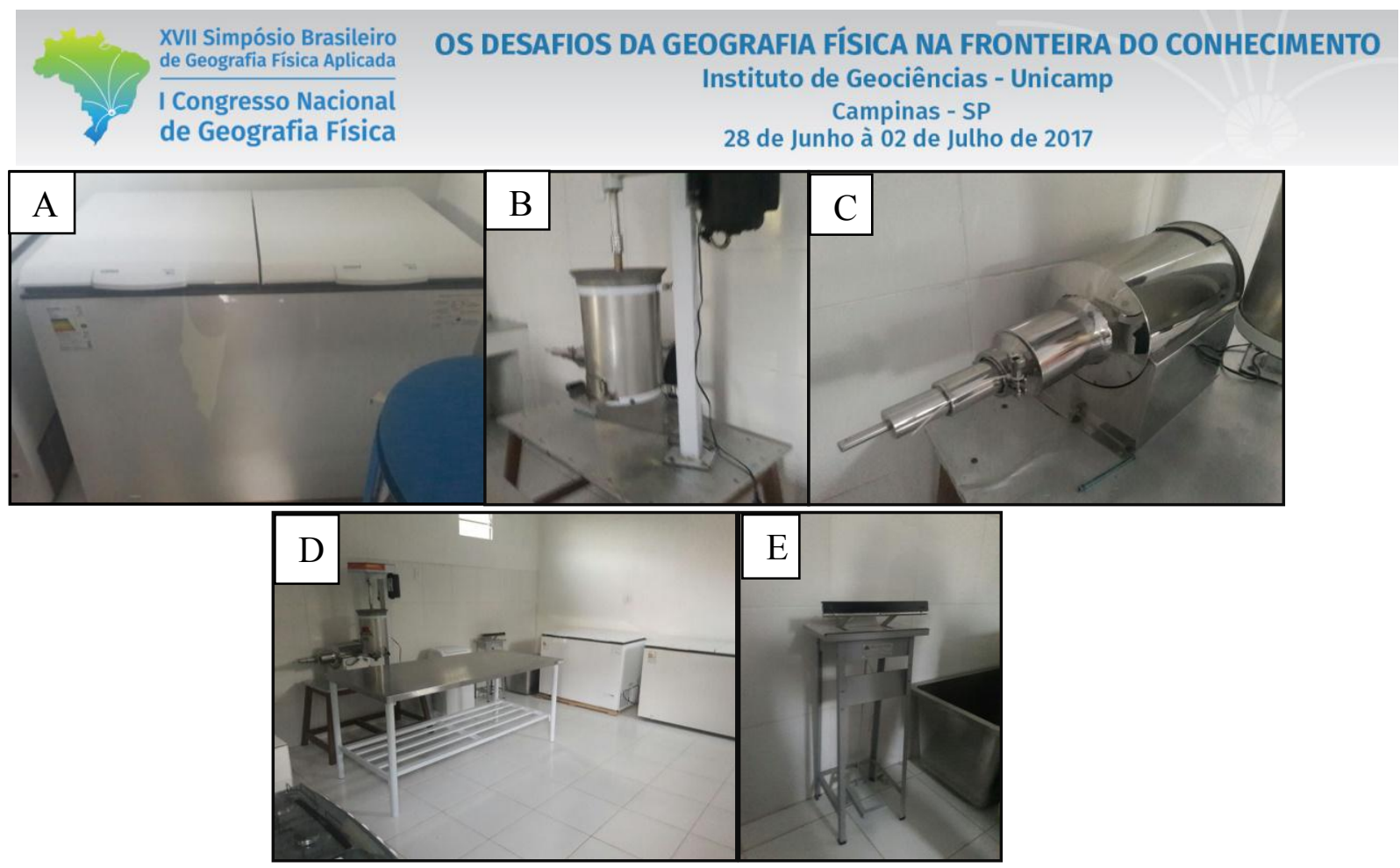

Figura 1: Equipamentos necessários para a realização das atividades da associação a) Freezer b) Despolpadora c) Dosador d) Seladora e) Sala equipada com os equipamentos necessários para a produção das atividades

\section{Conclusão}

A partir de dados levantados ao longo do estudo sistemático observa-se que o agronegócioé o modo de subsistência frequente naAssociação das Mulheres Agroextrativistas da Comunidade de Ajó - AMA, com a finalidade de venda para o mercado externotornando estreita a relação com o setor urbano, proporcionando uma renda extra para a família dessas empreendedoras. Diante das adversidades, a associação mostrou que união em conjunto com almejo de prosperar é um incentivo a mais para buscar evoluir em decorrência das dificuldades.

Agradecemos a Faculdade de Geoprocessamento da Universidade Federal do Pará, campus Ananindeua à logistica para a região de Cametá, ao Prof Enilson da Silva pelas informações acadêmicas imprencidiveis e a Associação das Mulheres Agroextrativistas da Comunidade de Ajó - AMA pelos relatados apresentados primordiais para confecção do presente trabalho.

\section{Bibliografia}

CARDOSO, A. S; TAVARES, F. B. Importância socioeconômica da horticultura nos sistemas produtivos familiares de uma comunidade do Baixo Tocantins (Pará). Cadernos de Agroecologia, v. 10, n. 3, 2016.). 


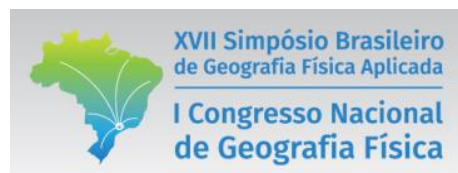
OS DESAFIOS DA GEOGRAFIA FÍSICA NA FRONTEIRA DO CONHECIMENTO
Instituto de Geociências - Unicamp
Campinas - SP
28 de Junho à 02 de Julho de 2017

Disponível em:http://consuladodamulher.org.br/premio-consulado-da-mulher-2015-beneficia-20-grupos-demulheres empreendedoras/Acesso em 14 de março de 2017, às 17h. 